'We have got the Tools': Qualitative Evaluation of a Mental Health Wellness

Recovery Action Planning (WRAP) Education Programme in Ireland

\title{
Citation
}

Keogh, B., Higgins, A., Devries, J., Morrissey, J., Callaghan, P., Ryan, D., Gijbels, H. and Nash, M. (2014) 'We have got the tools': Qualitative evaluation of a mental health Wellness Recovery Action Planning (WRAP) education programme in Ireland. Journal of Psychiatric and Mental Health Nursing, 21(3), pp.189-196.

\section{Accessible Summary}

- Because recovery is an important idea, an educational course was run to help service users and professionals to introduce Wellness, Recovery, Action Planning to interested parties in their communities.

- The evaluation of this course made use of group interviews in which participants were asked about their experiences on the course.

- Although they enjoyed the course and were positive about recovery and WRAP, they felt that they still lacked confidence in the presentation skills that they felt they required.

\begin{abstract}
In recent years there has been a consistent drive to incorporate Recovery principles into the Irish Mental Health Services. A group of Irish Mental Health Service Providers came together and delivered a five day Wellness, Recovery Action Plan (WRAP) facilitator's programme. The programme was developed and delivered by key stakeholders including people with self experience of mental health problem. This paper presents the qualitative findings from an evaluation of these facilitator's programmes. Three focus groups were held with twenty two people, the majority of who described themselves as mental health professionals and/or people with self experience of mental health problems. Data was analysed using a thematic approach and yielded four themes. Although the participants were positive about the programme and felt that their knowledge of recovery and WRAP had improved, they felt that they still lacked confidence in terms of the presentation skills required for facilitating Recovery and WRAP programmes. The findings suggest that Mental Health Service providers who wish to develop service users and clinicians as WRAP facilitators need to put more emphasis on the provision of facilitation and presentation skills in the programmes they develop.
\end{abstract}


Key Words: Recovery, Education, Wellness Recovery Action Plan (WRAP), Evaluation

\title{
Introduction
}

A review of the international mental health literature suggests that there is a strong interest in the incorporation of Recovery concepts into the organisation and delivery of mental health services in several countries, most notably the United States, New Zealand, Scotland and England (Mental Health Commission Ireland, 2005, Department of Health \& Children, 2006, , Higgins et al, 2012). The most widely cited definition of Recovery is Anthony's (1993) which defines Recovery as:

\begin{abstract}
'A deeply personal, unique process of changing one's attitudes, values, feelings, goals, skills and roles. It is a way of living a satisfying, hopeful and contributing life even with the limitations caused by the illness. Recovery, involves the development of new meaning and purpose in one's life as one grows beyond the catastrophic effects of 'mental illness' (Anthony, 1993:12).
\end{abstract}

In this context, it is clear that Recovery is more than just the reduction or remission of symptoms but is wider in terms of the individual's ability to adjust to these symptoms and lead a life that is full and complete (Mental Health Commission, 2005). Seeking to redirect and invigorate the Irish Mental Health Services, the Mental Health Commission (2005) and the Department of Health \& Children (2006) published policy and guidance documents calling for the introduction of Recovery orientated practices throughout the psychiatric services. This was part of an overall re-orientation of the mental health services which had been criticised for relying too heavily on hospitalisation and medication (Amnesty International, 2003; Department of Health \& Children, 2004a, 2004b). This reorientation is in line with international trends in mental health care provision and recognises the need for service users and professionals to alter their perceptions of mental illness as being lifelong and chronic. Central to Recovery oriented services are the development of hope inspiring relationships, the instillation of self help and self resourcefulness techniques and the involvement of service users in every aspect of mental health care provision (Fisher, 
1994; Higgins \& McBennett, 2007). However, for Recovery orientated mental health services to be realised, it is necessary that the relevant stakeholders are provided with education about the principles and philosophy of recovery (Higgins et al., 2010). To this end, a group calling themselves the Irish Mental Health Recovery Consortium (IMHREC) came together to plan and deliver a recovery oriented educational programme. The consortium comprised of mental health service users, their families, carers and practitioners. The focus of the IMHREC programme was to equip service users, family members and carers, and mental health professionals with knowledge about Recovery and Wellness Recovery Action Planning (WRAP) as well as skills to facilitate sessions in which these principles and skills are communicated to other interested parties. The authors of this article were commissioned to evaluate this educational programme using a mixed methods design.

\section{Wellness, Recovery, Action Planning (WRAP)}

Wellness Recovery Action Planning (WRAP) is a self management programme developed in the United States by a group of individuals who have lived experience of mental distress. Central to WRAP is the development of a plan which focuses on the maintenance of wellbeing and interventions for managing potential stressors which may negatively influence mental health (Scott \& Wilson, 2010). The WRAP approach is well known internationally, with mental health services in many countries adopting it as their preferred self management programme (Slade, 2009; Cook et al., 2009). However, research on WRAP's effectiveness has been slow to emerge (Cook et al., 2011; Starnino et al., 2010). There have been some evaluations and these have demonstrated positive outcomes in terms of hope and recovery orientation (Starnino et al., 2010) as well as symptom improvement and confidence in managing own recovery (Cook et al., 2009). Higgins et al (2012), in their pre and post test evaluation of a WRAP education programme, also found that it had a positive impact on beliefs, attitudes and knowledge about recovery. Cook et al (2011) conducted a randomised controlled trial to test if a WRAP group experienced greater symptom reduction than their control counterparts. Using the Brief Symptom Inventory, the experimental group participants experienced significantly 
reduced symptoms over time as well as improved hopefulness scores (Cook et al., 2011). These results demonstrate the effectiveness of WRAP in areas that are traditionally associated with recovery.

\section{The Irish WRAP Education Programme}

The education programme consisted of a two day education programme which gave participants an introduction to recovery and wellness principles culminating in (and assisting participants with) developing their own action plan using these principles (WRAP). A five day programme was also delivered to a smaller number of participants who had completed the two day programme. The purpose of the five day programme was to give a greater level of understanding about Recovery and WRAP to the participants as well as preparing them to deliver the two day programme within their own communities. The five day programme consisted of advanced information about Recovery and WRAP as well as giving participants a chance to practice their presentation skills within the safety of a group presentation. The programme was developed and delivered by facilitators who were themselves mental health service users as well as practitioners and had extensive experience of delivering recovery education programmes. Selection for the five day programme was based on the participants' willingness and ability to facilitate the two day programme to the widest possible audience. The five day programme was delivered in three locations around the country to a total of 67 participants who were selected from 117 applications from people who completed the two day training. Both the 2day and 5-day programmes were facilitated by a lead facilitator from the UK, with extensive recovery facilitation experience and who identified himself as a mental health service user. The qualitative findings from the evaluation of the five day facilitator's programme is the focus of this paper.

\section{The Study}

The aim of this study was to explore participants' experience of participating in a five day facilitator's programme on Recovery and WRAP, which aimed to equip them with the skills to deliver Recovery based programmes within a community context. 


\section{Methodology}

The full study employed a mixed methods design incorporating pre-post questionnaires and focus group discussion. Findings from the questionnaires are reported elsewhere (Higgins et al 2010, Higgins et al 2012). The focus groups were facilitated by two members of the research team, a facilitator and a moderator, and the discussion was guided by a topic guide (see Table 1). In order to get an in-depth understanding of participant's experience of the programme focus groups were completed at the end of each of the five day programmes. Information about the scope and purpose of the focus group was reiterated to the participants at the beginning of the interview. The role of the facilitator was primarily to ensure a flow of discussion and that of the moderator to monitor the focus group and support the facilitator. The interview covered five general areas of interest (see Table one). All participants were invited to share their perspectives and given time to do so. Additional topics were welcomed and discussed as they were brought up.

\begin{tabular}{|c|}
\hline $\begin{array}{l}\text { How have you experienced the } 5 \text { day WRAP } \\
\text { programme you attended? }\end{array}$ \\
\hline $\begin{array}{l}\text { What do you intend to do with the } \\
\text { material/the learning? }\end{array}$ \\
\hline $\begin{array}{l}\text { In your opinion, to what extent has this } \\
\text { programme prepared you to be a facilitator } \\
\text { of future WRAP programmes? }\end{array}$ \\
\hline $\begin{array}{l}\text { We are also wondering how the } 5 \text { day } \\
\text { WRAP facilitation programme compares to } \\
\text { other mental health facilitation } \\
\text { programmes you know about and/or have } \\
\text { experienced? }\end{array}$ \\
\hline $\begin{array}{l}\text { What advice would you give for the further } \\
\text { development of the } 5 \text { day WRAP } \\
\text { programme for facilitators? }\end{array}$ \\
\hline
\end{tabular}

Table 1: Summary of Interview Topic Guide

In each group, participants were exceptionally willing to share their experiences and opinions freely with considerable evidence of synergy within the groups. This enthusiasm led to an interactive flow of conversation throughout the interview. 


\section{Recruitment and sample}

Participants' were invited to take part in the focus groups through an opt-in form administered when the quantitative data was being collected at the end of the programme. Of the 67 participants who attended the 5-day training programme 22 people agreed beforehand to participate in three focus groups (FG1 $n=8, F G 2 n=8$, FG3 $n=6)$. There were eight men and fourteen women and the participants described themselves as coming from a variety of backgrounds, which frequently included dual identities of family member and service user or practitioner and service user (see Table 2). Overall, $45 \%$ of participants had self experience of mental health difficulties.

\begin{tabular}{|c|c|}
\hline Self Description & $\%$ \\
\hline Mental health practitioner only & $36 \%$ \\
\hline Person with self experience only & $18 \%$ \\
\hline Mental health practitioner and carer/family member & $9 \%$ \\
\hline Self experience and mental health practitioner & $9 \%$ \\
\hline Self-experience and carer/family member & $9 \%$ \\
\hline Self experience, MHP and family member/carer & $9 \%$ \\
\hline Other (mental health advocate/counselling student) & $9 \%$ \\
\hline Total & $\begin{array}{l}22 \\
100 \%\end{array}$ \\
\hline
\end{tabular}

Table 2: Breakdown of participants' self-description

One of the principles underpinning the programme was the premise that 'everyone is in the process of recovery'. Thus, participants and facilitators in the educational encounter were to be simultaneously helper, helped, facilitator and participant (Copeland Center for Wellness \& Recovery, 2009a). Given this context participants were not required to give details of the extent of their contact with mental health services or diagnostic labels that they may have received during such an encounter.

\section{Data analysis and rigor}


All focus groups were audio recorded and transcribed for analysis. Prior to analysis transcriptions were cleaned of any identifying information and compared with audio recordings for accuracy. A thematic analysis was conducted using an approach described by Braun and Clarke (2006). In line with this approach, data were analysed by coding for key ideas, concepts and patterns, which were then compared for similarities and difference and merged into higher order themes. To enhance the rigour of the analytic approach, two researchers analysed the data and then compared their findings. The analysis was also informed by the field notes which were taken by the group facilitator and moderator. Interviews were listened to a number of times and the transcripts were read and reread to help the researchers immerse themselves in the data. A set of themes were then drawn up from the codes which described the participants' experiences and perceptions of the course. Methods used to enhance the trustworthiness of qualitative data included the collection of data from participants who attended the three centres and the use of participants' narratives to substantiate claims made about the data. As a topic guide was used to guide the focus groups, it was not necessary to use qualitative data analysis software. Participants were also offered the opportunity to review transcripts; however, no participant took up the offer.

\section{Ethical issues}

Ethical approval was sought and obtained from the Research Ethics Committee at the Faculty of Health Sciences, Trinity College, Dublin. Prior to interview all participants signed written consent forms.

\section{Results}

The analysis of the qualitative data resulted in the emergence of the following themes:

1. Enhancing knowledge and skills of Recovery and WRAP for own life

2. Using WRAP within own Life

3. Having enthusiasm but lacking confidence to facilitate

4. Implementing and sustaining Recovery and WRAP into the future 


\title{
Enhancing knowledge and skills of Recovery and WRAP for own life
}

Overall the participants discussed the programme in a positive way and spoke of it as inspiring, invigorating and empowering. There was a strong sense that they valued and learned a lot from attending the five day training because it increased their knowledge and understanding of Recovery and WRAP.

'It just brought it to a whole new level for me having these five days. So I was completely impressed with the five days in terms of the group work and we, we'd break all the you know break it down, it was reinforced learning the whole time. And I thought that really set the scene for us going out to facilitate others but obviously the big thing was we had to do it ourselves' (FG3, Female).

The programme gave participants confidence and promoted self-esteem. In addition, several spoke about learning new techniques and strategies from using the facilitators' resource pack

\begin{abstract}
'Just one thing I just love is the resource pack, I think every question you could possibly have, it seems to be in it and whatever isn't in it there's a list of other resources you can look up yourself for further reading. I just think its fantastic, the $C D$ was great because you can have it on your computer, you can share it with other people fairly easy' (FG3, Male).
\end{abstract}

The focus of recovery and WRAP on helping yourself and on taking responsibility for your own mental health was mentioned often and this approach was perceived by the participants to be both refreshing and positive. Furthermore, people who described themselves as being users of the service felt that being able not only to share their experiences but to use them to help others validated their experiences and further heightened their sense of achievement and personal satisfaction. Furthermore, working in groups, and listening to the wealth of knowledge and experiences and other people's stories helped participants to understand and learn the processes and concepts associated with WRAP. Being free to tell their own story was highly valued as one participant stated: 
'telling our story and being listened to, that really was a big part of

it [the learning] for me' (FG2, female).

\section{Using WRAP within own life}

The main reasons that the participants gave for attending the WRAP facilitator's education programme were to gain knowledge and skills that they could apply to their own lives. There was variation in terms of how the participants utilised WRAP in their daily lives. Some used it in an elective fashion, dipping into various aspects to suit their own individual needs or as a complement to other mental health treatments whereas other participants fully immersed themselves in the concepts and adhered closely to the WRAP programme.

'It gave me power to help myself, something that was never discussed with me ever as a mental health patient. And I operated the plan myself and I found it seeped into me. It's actually in my mind now, without me being consciously thinking about it. It's operating in my mind. I don't have to go back to the book. It's also changed my language, everything has changed in me in how I do things' (FG1, Female).

There was a different interpretation of the facilitation programme for the participants with self experience and those who considered themselves as professionals. Those with self experience were more likely to perceive WRAP as something to not only incorporate into their own lives as well as teaching other people, whereas the professionals perceived it as a tool that they could use in their daily practice to help other people. Some of the participants were actively implementing WRAP in their daily practice as mental health professionals and even though some of the participants had utilised different aspects of WRAP in the past, it was the logical and coherent organisation of WRAP that made it both user friendly and practical.

'I have come away now with a set programme that you can put in place and its easy and workable where before I used one aspect of it or two aspects of it but now my understanding of the process that you can go through and there is step to step guide nearly that you can do with people and you can change that depending on if you are going to use with individuals or in groups or in a one to one or talking to professionals or talking to service users' (FG3, Female). 
Having enthusiasm but lacking confidence to facilitate

The second reason that the participants gave for attending the WRAP facilitator's education programme - and one of the main reasons it was offered - was to help other people to develop their own WRAP. While participants were very enthusiastic about becoming involved in developing and facilitating recovery and WRAP education, and many felt empowered "to go out and help other people", many of them stated that the course had not met their needs in learning the necessary facilitation skills and expressed a lack of confidence about facilitating a recovery and WRAP programme. This lack of confidence was especially evident among those who had never facilitated groups or educational sessions before. The following two quotations sum up this perspective, the first quote is from a participant who had facilitated other group sessions and the second quote is from a participant who had little previous experience:

'I have to say the consortium for me personally got it fairly well right, I'm very happy because I felt it complemented what I had, and I thought it was good for me. But I think ...if it was designed to teach people how to facilitate a WRAP program it didn't do that' (FG 1, Male)

I'm not familiar with that side of it. So if I had to put together a [WRAP] programme I'd have to spend quite a lot of time doing that' (FG1, Female).

Despite this, many acknowledged it would take time to gain experience in delivering the programme and that their confidence was likely to increase with time and experience.

'We have got the tools really; we have got the tools... [but]...I will not be comfortable with it until I have delivered it a few times' (FG2, Male).

Others planned to increase their confidence and overcome fears by working with a co-facilitator (i.e. with an experienced facilitator), and spoke of the importance of a mentorship scheme. 
'One of the things I'd like is an apprenticeship and to work with a mentor... you do your apprenticeship for a couple of months and then you get your driving licence' (FG1, Male)

\section{Implementing and Sustaining Recovery and WRAP.}

Participants' were concerned about how Recovery and WRAP could be sustained. They believed that the future of the Mental Health Services in Ireland could be influenced by the philosophy and language underpinning Recovery. Notwithstanding the obstacles described in the next section there was an overwhelming sense that the participants were committed to sustaining and developing WRAP, although there was no clear conceptualisation of how this would be achieved in practice. Central to this was the lack of certainty about the future of IMHREC who were perceived as the drivers behind the implementation of recovery and WRAP. Consequently their continued existence and recognition of their importance at a national level was seen as key to the longevity of Recovery and WRAP. Furthermore it was suggested that the Irish Mental Health Commission which oversees the mental health services in Ireland, needs to have a pivotal role in implementing the concepts of Recovery.

Many of the participants offered suggestions to how recovery could be implemented successfully, but these were more at a practical level rather than at a strategic or organisational level. Examples of these included having an apprenticeship model of facilitation or nominating a mentor for facilitators. The participants also felt that there should be a formal support network for facilitators Participants also thought that introducing Recovery and WRAP into schools would be a good way of educating younger people about mental health. Others suggested that the sustainability of WRAP lies in its flexibility and diversity of application, citing examples of the various groups of individuals who might benefit from Recovery and WRAP (for example, people within the prison system).

'Somebody asked me about a pre-release program in the prison near where I live in [names town] and I thought that I could actually integrate it into the pre-release program. I've been asked to do something on mental health and I thought this might be an opportunity. It's a simple program because when prisoners are 
leaving the prison they have concerns and fears in the same way as people leaving hospitals' (FG3, Female).

The participants discussed a number of barriers to implementing the concepts associated with recovery and the WRAP programme. These barriers mainly revolved around challenging the traditional approach to the mental health services in Ireland which is dominated by biomedical approaches. The major obstacle here stemmed from the movement of the mental health services from its present preoccupation with 'illness' to one of 'wellness'. Furthermore, it was believed that implementing recovery and WRAP requires a coherent national strategy that would have major financial implications for an already cash starved mental health service. Tied to this barrier was a lack of input and participation from medical personnel. This could make incorporating Recovery and WRAP with conventional mental health services very difficult, not only at an organisational level but also at a philosophical level as well. This is highlighted in the following quotation:

'Not a lot of consultants would be interested in what we are doing. They are still looking at a medical model. And I suppose we as practitioners in developing, it's part of our mission statement to educate them' (FG2, Male).

This lack of 'buy-in' from those with perceived control over the mental health services would make the dissemination of the core values difficult to people who may not yet have heard of the Recovery model or were resistive to changing current beliefs and practices. The participants also felt that persistent and pervasive negative attitudes towards people with mental illness and people who use the services would be impossible to change if everybody was not on board. This philosophical shift was not just limited to mental health professionals but also service users who perhaps adopted a passive and non contributory role in the management of their own mental health. Linked to this is a perceived lack of co-ordination and consistency between mental health services throughout the country which the participants believed would also have a negative impact in terms of implementing the recovery concepts, further emphasising the need for a national strategy rather than local initiatives.

\section{Discussion}


This article has described the qualitative results from the evaluation of a Recovery and WRAP education programme which aimed to equip participants with the skills to facilitate a two day Recovery and WRAP education programme in their own communities. The programme designed by IMHREC endeavoured to create a ripple effect by introducing Recovery and WRAP to key people and then preparing Recovery and WRAP facilitators to continue the work that IMHREC began. While a number of studies could be located which evaluated WRAP education programmes, studies which specifically evaluated a WRAP education facilitator's workshop are sparse.

Although the programme participants in this evaluation were positive about Recovery and WRAP and looked forward to their roles as facilitators, its success in terms of preparing participants to facilitate WRAP programmes was reported as limited. The participants reported a perceived lack of confidence in their ability to become instructors or facilitators of WRAP, supporting Terry's (2010) assertion that it takes more to being a facilitator than just being able to read the supporting documentation. Although the participants in this study recognised that their knowledge of Recovery and WRAP still required development, they were satisfied that the information and resources were available to them. However, there was little if any discussion about core facilitation skills and to what extent the participants felt prepared from a presenter/instructor point of view. In Terry's (2010) study, the participants identified that skills such as the promotion of reflection, mental health expertise, prior experience of training and an ability to manage emotional labour were essential skills needed for mental health first aid instructors. Furthermore, it was believed that instructors needed to be able to respond appropriately to diverse situations as well as being able to handle the potential distress that might emerge. Issues such as these were not discussed during the WRAP facilitator's course; therefore it is not surprising that some participants felt unprepared. Furthermore, in Stevenson and Elvy's (2007) evaluation of mental health first aid training in Scotland, their participants valued gaining experience delivering course content and would like to have received more information on IT and audio visual equipment again stressing 
the need for courses like this to be practical rather than theoretical. The main preparation for facilitation, in the study reported here, came in the form of a group presentation which the participants worked on over the five days. It could be that the participants in the WRAP facilitator's course overlooked the complexities of the teaching skills required as they were not raised during the 5 days. It appears that emphasis was on the content and structure of WRAP and ensuring that the participants were knowledgeable about it rather than the intricacies of how they should organise and deliver this content to a group of people. In addition the facilitator's experiences of recovery may have stemmed from 'doing recovery' rather than 'talking about recovery' which may have further emphasised his experiential knowledge rather than core facilitation skills.

Because the presentations and the focus groups were held on the last day of the course, participants may not have had the time to reflect adequately on the content of the course or the strategies that they might use to deliver it. In retrospect, this may be an important limitation of this study. In short, the timing of the evaluation did not permit people to try out their new learning and check out to what extent they were prepared for facilitating or co-facilitating WRAP sessions. Furthermore, there was little scope for follow up or support for the novice facilitators due to the closure of IMHREC. In Happell and Roper's (2003) study, support for the consumer academic came from the establishment a project team. While IMHREC were seen as the primary support for the novice educators in this evaluation, their disbandment shortly after the delivery of the workshops was perceived by the participants as negative. Consequently, the participants suggested the introduction of a mentorship scheme to assist novice facilitators gain confidence which has been introduced in an ad hoc way. However, since the workshops ended, social media sites such as Facebook and Linkedin have provided the participants with forums for airing and sharing new ideas, providing support and contact between members. In light of this is it is the intention of the team to do a follow up study of this group of people to see if, and how they have used their knowledge within the community. The closure of IMHREC is unfortunate given that one of the outcomes of the workshops was 
capacity building. The expectation that outcomes such as these would emerge in an organic way are endemic to the way that funding is often allocated; without consideration of the supports that are required to achieve sustainability.

The current drive with services is to adopt a partnerships approach and incorporate people with self experience, family members and practitioners in recovery education and this viewpoint is supported by Happell and Roper (2003). There is no doubt that this tripartite approach to education is the way forward and was perceived by the participants as positive and beneficial. What is interesting about the profile of the participants in this study was the dual and triple nature of people's identities, with participants describing themselves as coming from more than one group. Given this experience the authors do question if the binary division perpetuated by the labels service user and practitioner only serves to reinforce stigma and a 'them' and 'us' culture, making it difficult for people who are both user and practitioner to be open about their experience within a stigmatising mental health service culture. Practitioners who identify themselves as service users have a clear contribution to make to recovery leadership within organisations, however they may need to deconstruct their understanding of Recovery given that the systems in which they work may focus on traditional conceptualisations of Recovery. These individuals would not be seen as a replacement for people who are working from a consumer movement perspective but as a positive influence and support to consumer led practice (Queensland Voice for Mental Health Inc, 2012).

\section{Conclusion}

Repper and Breeze (2007) found in their review of user involvement in the training and education of health professionals, that there was a paucity of research or evaluations of how service users are prepared for their role as educators. However they do argue that training and support are needed. Similarly, Towle et al's (2010) review found that the preparation received by service users varied considerably but 
did reduce anxiety. Given the complexity of the skills required to facilitate a two day recovery and WRAP workshop, this facilitators course might have benefited from delivering specific presentation and teaching skills to the participants. For example, skills like managing group work, asking questions and giving feedback are difficult to manage and may require practice. In addition allocating mentors to newly trained facilitators may also help. In this course the participants valued learning together with service users, carers and mental health professionals although they were critical of the balance between the three groups. Although there was some time for discussion, the prescriptive nature of the WRAP facilitators programme and the concentration on ensuring that participants understood the concepts associated with Recovery and WRAP may have resulted in process orientated outcomes being overlooked. In addition, given the structured nature of the two day programme, facilitators had little scope to bring in their own experiences regardless of their background. 


\section{References}

Amnesty International (2003) Mental Illness: The Neglected Quarter. Amnesty International Irish Section, Dublin.

Anthony W.A. (1993) Recovery from mental illness: The guiding vision of the mental health service system in the 1990s. Psychosocial Rehabilitation Journal 16(4), 11-23.

Braun V. \& Clarke V. (2006) Using thematic analysis in psychology. Qualitative Research in Psychology 3, 77-101.

Cook J.A., Copeland M.E., Jonikas J.A., et al. (2011) Results of a randomised controlled trial of mental illness self management using Wellness Recovery Action Planning. Schizophrenia Bulletin, DOI:10.1093/schbul/sbr012

Copeland Centre for Wellness \& Recovery (2011) 'What is WRAP?'. http://www.copelandcenter.com/whatiswrap.html (accessed 13.11.2011).

Department of Health \& Children (2006) 'A Vision for Change' Report of the Expert Group on Mental Health Policy. Stationary Office, Dublin.

Department of Health \& Children (2004a) Speaking your Minds. Stationary Office, Dublin.

Department of Health \& Children (2004b) What We Heard. Stationary Office, Dublin.

Fisher D.B. (1994) Health care reform based on an empowerment model of recovery by people with psychiatric disabilities. Hospital Community Psychiatry 45(9), 913915. 
Happell B. \& Roper C. (2003) The role of a mental health consumer in the education of postgraduate nursing students: the students evaluation. Journal of Psychiatric and Mental Health Nursing 10, $343-350$.

Higgins A., Callaghan P., de Vries J., Keogh B., Morrissey J., Ryan D., Gijbels H. \& Nash M. (2010) Evaluation of the Mental Health Recovery and WRAP Education Programme: Report to the Irish Mental Health and Recovery Consortium. Trinity College, Dublin available at http://www.imhrec.ie/wpcontent/uploads/2010/08/TCD-Evaluation-Report-13-05-10.pdf

Higgins A., Callaghan P., de_Vries J., Keogh, B., Morrissey J., Nash M., Ryan D., Gijbels H. \& Carter T. (2012) Evaluation of mental health recovery and Wellness Recovery Action Planning education in Ireland: A mixed method pre-post evaluation. Journal of Advanced Nursing, DOI: 10.1111/j.1365-2648.2011.05937.x.

Higgins A. \& McBennett P. (2007) The petals of recovery in a mental health context. British Journal of Nursing 16 (14), 852 - 856.

Mental Health Commission (2005) A Vision for a Recovery Model in Irish Mental Health Services. Mental Health Commission, Dublin.

Repper J. \& Breeze J. (2007) A review of the literature on user and carer involvement in the training and education of health professionals. International Journal of Nursing Studies 44, 511-519.

Scott A. \& Wilson L. (2011) Valued identities and deficit identities: Wellness Recovery Action Planning and self management in mental health. Nursing Inquiry 18 (1), 40 49

Slade M. (2009) Personal Recovery and Mental Illness: A Guide for Mental Health Professionals. Cambridge University Press, Cambridge 
Starino V.R., Mariscal S., Holter M.C., Davidson L.J., Cook K.S., Fukui S. \& Rapp C.A. (2010) Outcomes of an illness self management group using Wellness Recovery Action Planning. Psychiatric Rehabilitation Journal 34 (1), 57 - 60

Stevenson R. \& Elvy N. (2007) Evaluation of Scotland's Mental Health First Aid. NHS Health, Scotland.

Terry J. (2010) Experiences of instructors delivering the mental health first aid training programme: a descriptive qualitative study. Journal of Psychiatric and Mental Health Nursing 17, $591-602$.

Towle A., Bainbridge L., Godolphin W., Katz A., Kline C., Lown B., Madularu I., Soloman P. \& Thistlewaite J. (2010) Active patient involvement in the education of health professionals. Medical Education 44, 64 -74. 